\title{
Closing Remarks at Monterey
}

\author{
By Walter Munk
}

T HE LAST THREE days have been quite an experience. I have welcomed the relaxed schedule. We all listened to the same program and had the same experience (not the usual fractured experience). It was somewhat like being together at sea for a short cruise (but not on a dry Woods Hole vessel). We are going home elated and a bit exhausted.

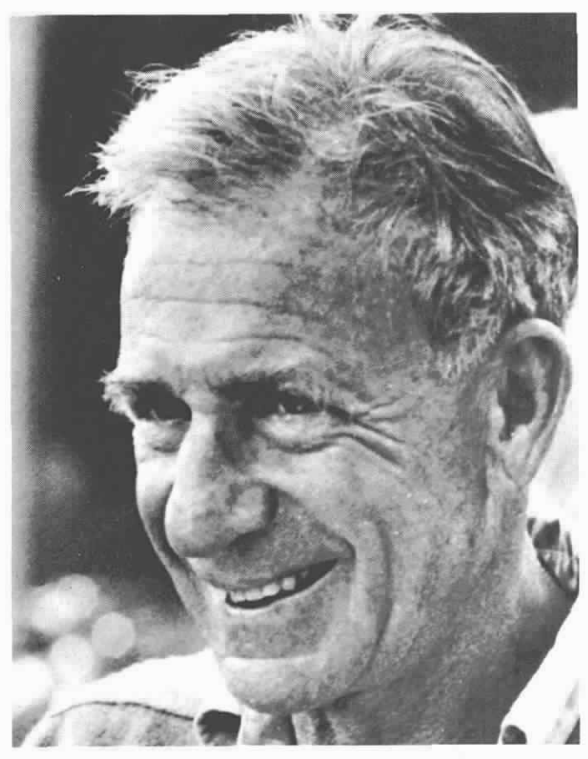

Walter Munk

We owe special thanks to our founding father, Jim Baker. He has organized things so well that his only noticeable activity seems to have been taking mug-shots of speakers.

David Packard did not create MBARI as a mature investment. In his opening remarks, David referred to the "mystery" and "frontiers" of the deep ocean and processes which "await discovery." MBARI was set up to explore the biology, chemistry and physics of Monterey Bay "... and the contiguous waters beyond...," quoting words similar to some I was able to sneak into the

Walter Munk, University of California, San Diego, Institute of Geophysics and Planetary Physics, A-025, La Jolla, CA 92093. charter. The driving force behind MBARI is David Packard's conviction that the ocean community has not taken full advantage of developments in remote sensing. When John Apel was trying to drum-up support for the remote-sensing satellite SEASAT, the ocean community received his advances without enthusiasm. After all, we heard, anything that is not done from ships is not oceanography. And, at an earlier time, anything that was not done from sailing ships was not oceanography.

In the same vein, Henry Stommel recalled a delightful story about Ray Montgomery asking Henry Bigelow's advice about a career in oceanography. Evidently, Bigelow advised against it, oceanography being done by gentlemen of independent means. Stommel is a living case history of exploration and discovery, and that pattern has not weakened with time.

And with regard to the last speaker [Walter is referring to himself: see his Review and Comment article in this issue.-Ed.], he can rightfully be accused of senility, but not of maturity (I have detected an inverse correlation between age and maturity at this meeting).

Trevor Platt has spoken of the revolution in biological oceanography brought about by satellites. I would like to think of the first century of oceanography (since the Challenger Expedition) as one-hundred years of undersampling.

If you go over the plans of classical expeditions, you have to come to the conclusion that they could not possibly have solved the problems they set out to solve even if all equipment had worked perfectly (which is not always the case). And we physical oceanographers have provided our biological colleagues with ocean descriptions so "dream-like" that they could not possibly have been of any use; anyone who claimed that they were useful must have been incompetent or dishonest. Sampling has its own stringent rules; one does not with impunity slight the Nyquist Sampling
Theorem.

This does not mean that you need forever more and more closely spaced sampling, but you do need adequate sampling. It is a fortunate accident that the resolution required for observing mesoscale processes (determined by ocean dynamics) matches the resolution available from satellite orbits (determined by celestial dynamics).

As a result of satellite monitoring, we are now furnishing useful charts of sea surface properties. Chemists are now making useful measurements (concentrations of trace chemicals are no longer diminishing year by year). Biologists find these measurements increasingly useful. It is time for the oceanographic disciplines to come together. It is time for an Oceanography Society.

John Knauss spoke of having witnessed the revolution of plate tectonics, and that he thought he would never witness a second revolution. He now believes that [science focused on] global change is bringing about a new revolution. We are fortunate to have an active and imaginative oceanographer at the helm of NOAA.

Participation in the Inaugural Meeting of TOS was like participating in a bit of history. I sense that we have felt comfortable in each other's company. Oceanographers have their own taste and culture. Is it because of our strong biological ties? (Who ever heard of ornithology being discussed at a meteorology meeting?) Or is it because of our tradition of life at sea?

As Henry Stommel put it, survivors are congenial people or they wouldn't be here. We thank the founders of TOS for their exploratory advance in bringing us together at Monterey.

Acronyms: MBARI, Monterey Bay Aquarium Research Institute; NOAA, National Oceanic and Atmospheric Administration; TOS, The Oceanography Society.

Editor's Note: We present these slightly edited remarks in the unadorned style of speaker's notes, hopefully to preserve their special flavor and warmth. 